\title{
Dynamic Response Analysis of Half-through CFST Arch Bridges Affected by Crossbeams Setting
}

\author{
Jun $\mathrm{Ma}^{1, a}$, Yan $\mathrm{Li}^{2, \mathrm{~b}}$ \\ ${ }^{1}$ School of Transportation Science and Engineering, Harbin Institute of Technology, China \\ ${ }^{2}$ School of Transportation Science and Engineering, Harbin Institute of Technology, China \\ amajunlxd@163.com, 'liyan_2007@126.com
}

\begin{abstract}
Keywords: bridge engineering; half-through CFST arch bridges; FEM; dynamic response; crossbeams
\end{abstract}

\begin{abstract}
As one of the most important components of CFST arch bridges, the cross beams should affect the bridges' dynamic performance and response magnificently by means of affecting these three factors mentioned above. Based on the Maocaojie Bridge, its FEM models of half-through CFST arch bridges with different settings of cross beams are built. The different seismic responses of six operating conditions are calculated with three dimensional earthquake waves input. The internal force and displacement envelope diagrams of arch ribs are extracted and analyzed in situations of in-plane moment, out-plane moment, vertical displacement and transverse displacement. It can conclude that the joint section between arch rib and bridge deck should be designed carefully because of its large displacement and internal force, and the cross beams should be optimized to safety the arch bridge dynamic response considering lateral rigidity. The conclusions may be useful to the seismic design and strengthening treatment of CFST arch bridges. To strengthen the joint section between arch rib and bridge deck or optimize the setting of cross beams will increase the ductility of half-through CFST arch bridge and decrease the damages caused by large earthquake.
\end{abstract}

\section{Introduction}

For half-through CFST (concrete filled steel tube) arch bridges, its main components are arch, cross beams, deck, suspenders, tied bar (especially to the tied arch bridge) and etc. every component would affect the bridge's dynamical character obviously.

As one of these components, cross beams can not only strengthen the transverse stability but also enhance the transverse stiffness and mass which cause the increasing response of arch rib under transverse earthquake wave especially to half-through and through type arch bridge. Since the transverse stability calculating method and seismic design method for CFST arch bridge are not perfect, some designers use over-strengthened cross beams to avoid lateral buckling. These treatments will cause waste and go against seismic safety especially to the bridges which locate at earthquake region[1]. References [2-4] analyzed the affection to the half-through CFST arch bridges' general mechanical behaviors which include the dynamic behavior by the setting of cross beams. These analysis paid more attention to the affection to arch bridges' natural frequency by the settings. The affections by deck, suspenders and tied bars are also being analyzed in Reference [5-6].

The dynamic time-history analysis method is often used in bridge structure dynamic analysis. This method is based on the D'Alembert principle which can indicate as dynamic equation below:

$$
[M]\{\ddot{\delta}\}+[C]\{\dot{\delta}\}+[K]\{\delta\}=-[M]\left\{I_{x}\right\} \ddot{\delta}_{g}(t)
$$

where: $[M],[C]$ and $[K]$ as structure's mass, damp and stiffness matrix, $\{\delta\}$ and $\ddot{\delta}_{g}(t)$ as time-history vector of structure node's displacement and ground acceleration. 
From the equation, it can figure out that there are three main factors which affect the structure's dynamic performance, the mass matrix, the stiffness matrix and the damp matrix. The cross beams, as one of the most important component of half-through CFST arch bridge, would affect the stiffness matrix and the mass matrix obviously. It is necessary to research the cross beams' setting and optimal design based on dynamic analysis.

\section{FEM Models of Different Crossbeam Settings}

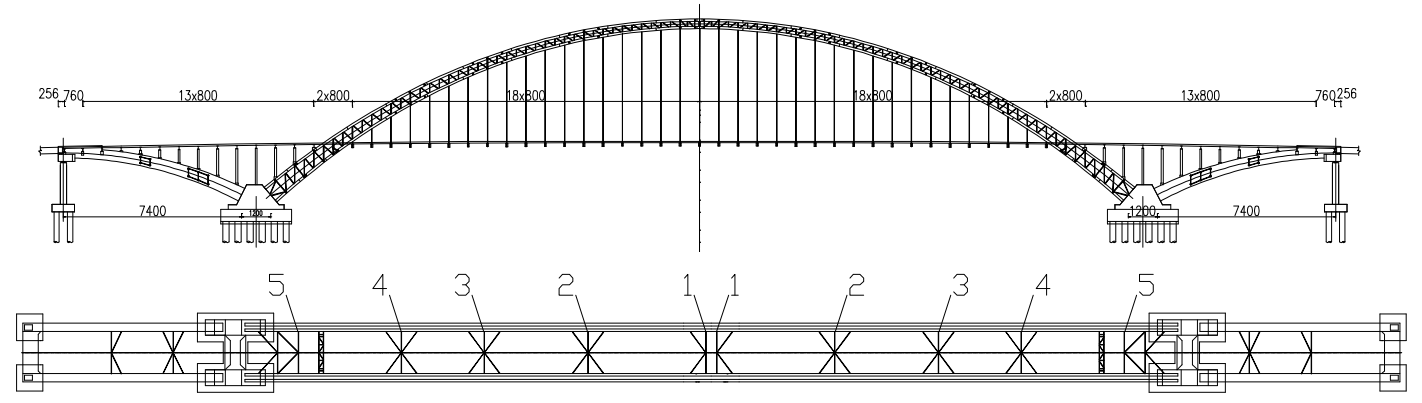

Fig. 1. Layout of Maocaojie Bridge and settings of cross beams

As a typical example, Maocaojie Bridge (showed in Figure 1) is a tied half-though CFST arch bridge with three spans $(80 m+368 m+80 m)$, catenary arch axis, $1 / 5$ as its rise-span ratio, and 1.543 as its arch-axis coefficient. The bridge has ten cross beams in shape of $\mathrm{K}$ type and $\mathrm{X}$ type (showed in Figure 1). According to this, the calculating analysis has four operating conditions (showed in Table 1). The $5 \#$ cross beam is under the deck and near the skewback. Its effect to dynamic response is not obvious because of the large stiffness of skewback, so the calculating analysis is mainly on the 1\#-4\# cross beams.

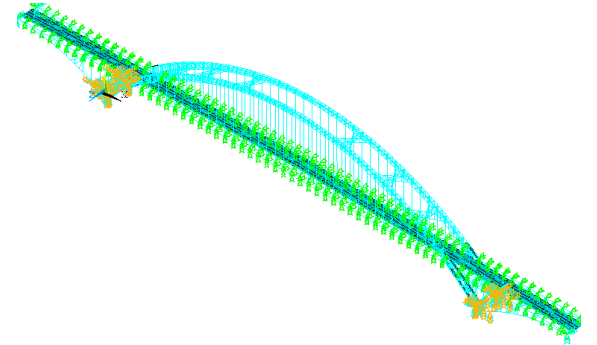

(a) Model of operating condition I

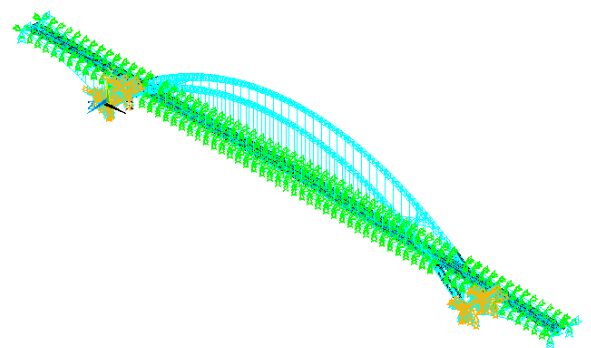

(c) Model of operating condition III

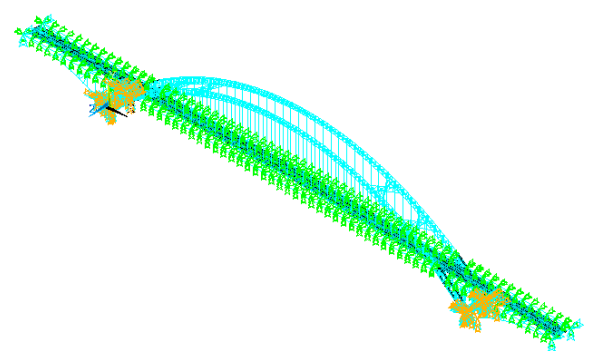

(b) Model of operating condition II

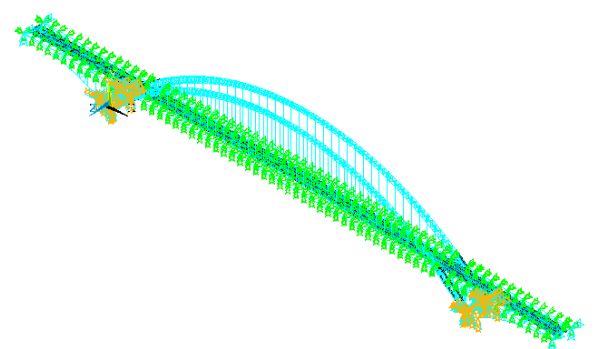

(d) Model of operating condition IV

Fig. 2 FEM models of Maocaojie Bridge

The FEM model of Maocaojie Bridge is built with general FEM program ANSYS. The arch elements are built with Beam 189 which is 3-D Quadratic Finite Strain Beam with user-defined cross section. The suspenders and tie bars are built with Link 10 which is Tension-only or 
Compression-only Spar. The decks are built with Shell 63 which is Elastic Shell. The other components are built with Beam 4 which is 3-D Elastic Beam. The model has 5325 elements and 2431 nodes totally.

Table 1 Operating conditions for Maocaojie Bridge's analysis

\begin{tabular}{cc}
\hline Operating condition & Description \\
\hline 1 & Model without 1\# cross beam \\
2 & Model without 1\# and 2\# cross beams \\
3 & Model without 1\# - 3\# cross beams \\
4 & Model without 1\# - 4\# cross beams \\
\hline
\end{tabular}

To verify the model, the static and modal analyses are carried on. The calculating results and those from Reference [7-9] are compared in Table 2 and 3.

Table 2 Results contrast of lower chord deflection in vault Unit (mm)

\begin{tabular}{|c|c|c|c|c|}
\hline \multicolumn{2}{|c|}{$\begin{array}{l}\text { Operating conditions (In Chinese } \\
\text { Standard of Bridge Design) }\end{array}$} & $\begin{array}{l}\text { Finished } \\
\text { dead state }\end{array}$ & $\begin{array}{l}\text { Serviceability } \\
\text { limit state }\end{array}$ & $\begin{array}{l}\text { Ultimate } \\
\text { limit state }\end{array}$ \\
\hline \multirow{3}{*}{ Displacement } & $\begin{array}{c}\text { Calculating Results of the } \\
\text { Model }\end{array}$ & 0.173 & 0.201 & 0.24 \\
\hline & $\begin{array}{c}\text { Calculating Results of } \\
\text { Ref. } 7\end{array}$ & 0.172 & 0.206 & 0.238 \\
\hline & Test Results of Ref. 7 & 0.189 & 0.193 & 0.252 \\
\hline
\end{tabular}

Table 3 Results of modal analysis

\begin{tabular}{|c|c|c|c|c|c|c|c|c|c|}
\hline \multicolumn{2}{|c|}{ Order of modal shape } & 1 & 2 & 3 & 4 & 5 & 6 & 7 & 8 \\
\hline 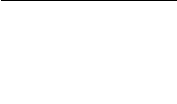 & $\begin{array}{l}\text { Calculating } \\
\text { of the Mode }\end{array}$ & ${ }_{1}^{\text {Results }} 0.240$ & 0.325 & 0.450 & 0.524 & 0.726 & 0.841 & 0.849 & 1.167 \\
\hline \multirow[t]{2}{*}{$\begin{array}{l}\text { Frequency } \\
(\mathrm{Hz})\end{array}$} & $\begin{array}{l}\text { Calculating } \\
\text { of Ref. } 8\end{array}$ & Results $_{0.240}$ & 0.367 & 0.446 & 0.467 & 0.660 & 0.790 & 0.820 & 0.940 \\
\hline & $\begin{array}{l}\text { Calculating } \\
\text { of Ref. } 9\end{array}$ & Results $_{0.234}$ & 0.325 & 0.364 & 0.459 & 0.565 & 0.784 & 0.842 & 0.962 \\
\hline
\end{tabular}

The static and modal analyses results inosculate with those in Reference [7-9] well. The FEM model is reliable.

\section{Earthquake Wave Input}

The El Centro wave is selected to calculate the time-history response of arch structure. The time interval is $0.02 \mathrm{~s}$, and load duration is 40 seconds. The peak values of accelerations are $0.313 \mathrm{~g}$ at NS, $0.199 \mathrm{~g}$ at WE and $0.205 \mathrm{~g}$ at $\mathrm{UD}\left(1 \mathrm{~g}=9.8 \mathrm{~m} / \mathrm{s}^{2}\right)$. The earthquake wave is inputted at three directions at same time to simulate the real condition.

\section{Analysis of Calculating Results}

The models of the four operating conditions are achieved by the program's the birth and death capability. The results of the four operating conditions are carried on with complicated FEM calculations. The Envelope diagram of moments and displacements in arch ribs are extracted to indicate the dynamic response of the bridge structures with different cross beam settings. 


\subsection{In-plane Moment $\left(M_{y}\right)$}

It can conclude from Fig. 3 that the four envelope diagrams of in-plane moment are nearly same in shape. With the reduction of cross beams, the maximum moments between $50 \mathrm{~m}$ and $150 \mathrm{~m}$ of arch rib are decreased, and the wave peaks are decreased from four to one. The biggest maximum moment of four conditions is operating condition 2 (without cross beam 1 and 2). The $2 \#$ cross beam effect the in-plane moment relatively larger than the others. It is $48 \mathrm{~m}$ away from arch crown which is $1 / 7.25$ of arch length.

\subsection{Out-plane Moment $\left(M_{z}\right)$}

It can conclude from Fig. 4 that the four envelope diagrams of out-plane moment are nearly same in shape. With the reduction of cross beams, the maximum moments appear between $50 \mathrm{~m}$ and $150 \mathrm{~m}$ of arch rib. The maximum value appears at $44 \mathrm{~m}$ away from skewback. The moments of operating condition 3 are larger than the moments of other conditions shows that the $3 \#$ cross beam is important to the out-plane moment response. It is $88 \mathrm{~m}$ away from arch crown which is $1 / 4.386$ of arch length.
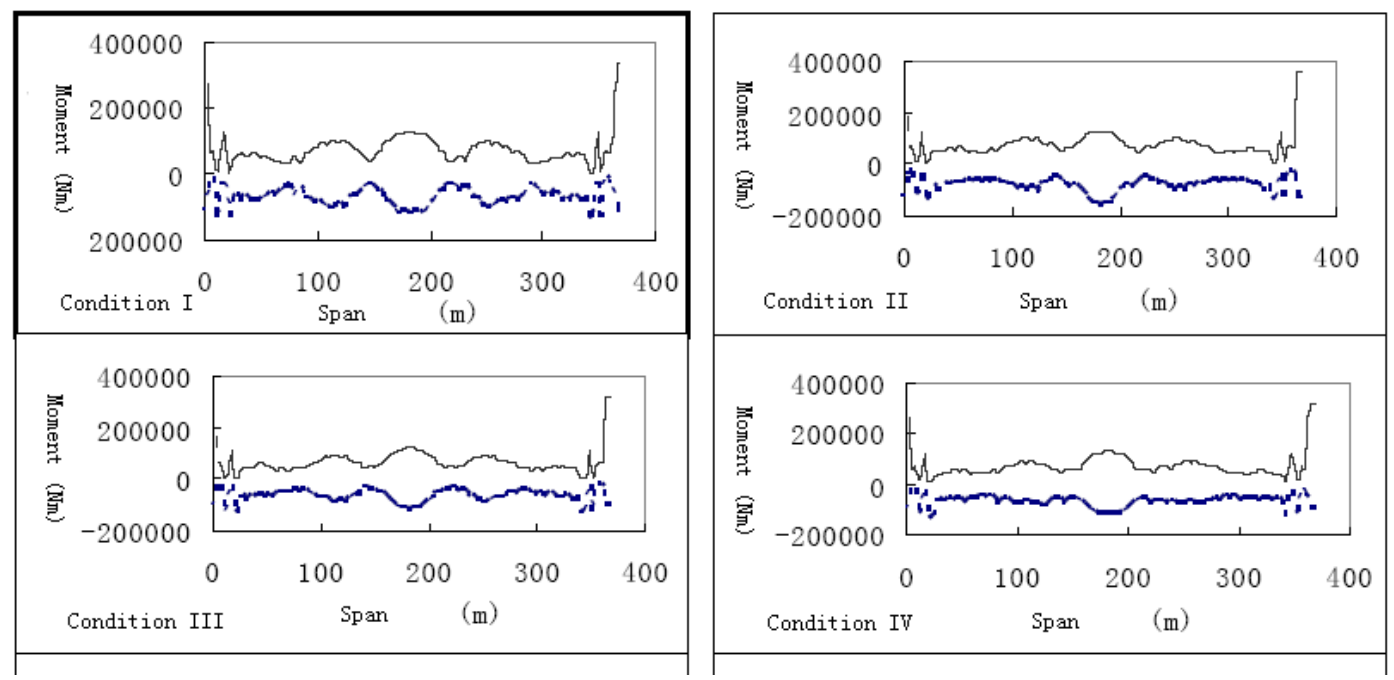

Fig. 3 Envelope diagram of in-plane moment
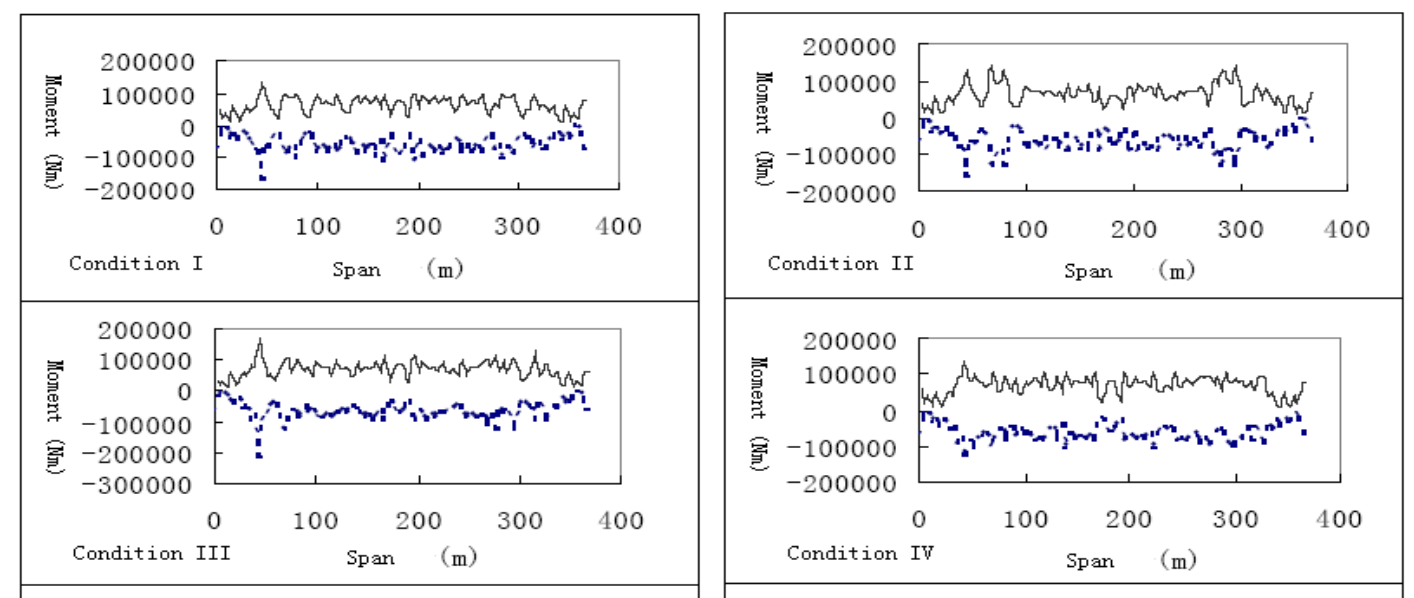

Fig. 4 Envelope diagram of out-plane moment

\subsection{Vertical Displacement (Y-Direction)}

It can conclude from Fig.5 that the four envelope diagrams of out-plane moment are changed regularly. The diagrams are symmetrical and the maximum displacement is about $0.03 \mathrm{~m}$ which appears at arch crown. In operating condition 1, there are two wave peaks beside the arch crown. As 
the decrease of cross beams, the peaks are abated. The maximum displacement is $0.307 \mathrm{~m}$ which appears in operating condition 2 shows that the $2 \#$ cross beam is effect the vertical displacement relatively larger than the others.

\subsection{Transverse Displacement (Z-Direction)}

It can conclude from Fig.6 that the four envelope diagrams of out-plane moment are changed regularly. The diagrams are symmetrical and the maximum displacement is about $0.018 \mathrm{~m}$ which appears at arch crown. As the decrease of cross beams, the transverse displacements are reduced and two wave peaks appear beside the arch crown. The cross beams strengthen the transverse stiffness, but cause the transverse displacement increased.
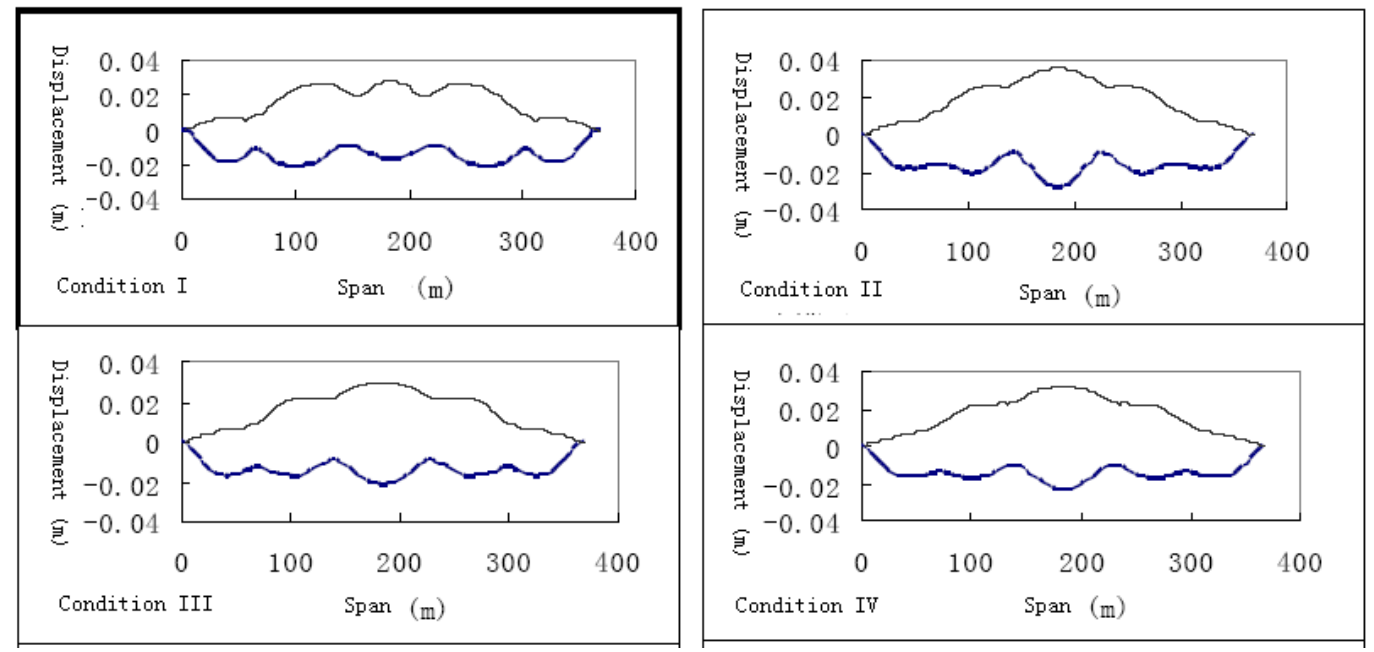

Fig. 5 Envelope diagram of Y-axial displacement
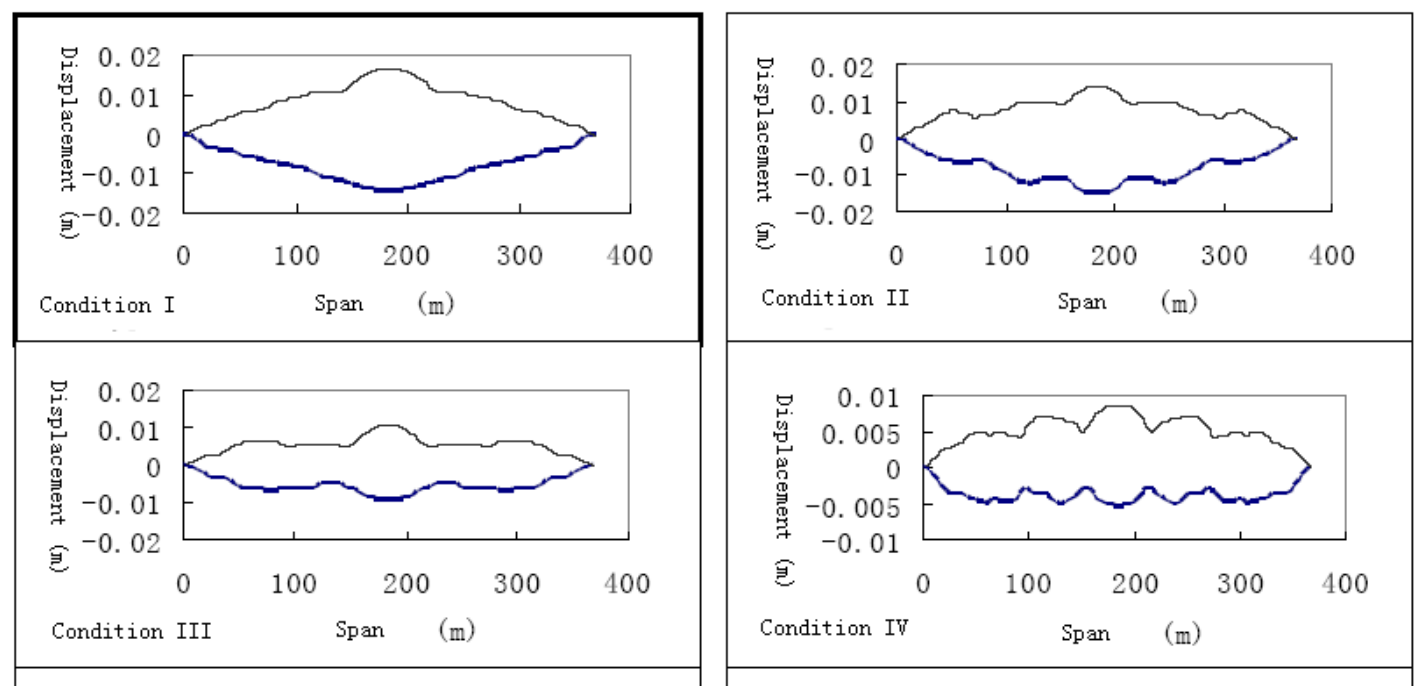

Fig. 6 Envelope diagram of Z-axial displacement

\section{Conclusion}

(1) The cross beams at $1 / 4$ span effect the out-plane dynamic response obviously and the one at $1 / 8$ span effect the in-plane dynamic response.

(2) The joint section between arch rib and bridge deck should be designed carefully because of its large displacement and internal force. 
(3) For the half-through CFST arch bridge, the cross beams mainly effect the out-plane dynamic response. With the cancellation of cross beams one by one, the arch crown displacement reduces step by step and the displacements between deck and arch crown increase step by step. The existence of cross beams has both sides effect on arch general seismic capability. Optimizing the setting of cross beams will increase the ductility of half-through CFST arch bridge and decrease the damages caused by large earthquake.

\section{References}

[1] Chen Baochun, Design discussion of CFST arch constructrues[C]. Proceedings of the 14th national conference on bridge structure, Nanjing, 2000, pp505-510

[2] Yun Di, Zhang Sumei, Influence of transverse braces arrangement on dynamic characteristics of half-through CFST arch bridge. Journal of Harbin Institute of Technology, 2003(sup): 259-262

[3] Wen Feng, Shou-ying, Liu Mu-guang, Duan Shu-jin, Effects of Transverse Brace Arrangements on the Dynamic Characteristics of CFST Arch Bridges, Traffic Engineering and Technology for National Defence(2007) 43-45

[4] Zhao Yueyu, Jin Bo, Lao Wenquan, Influence of transverse braces arrangement on mechanical characteristics of CFST arch bridge, Hunan Communication Science and Technology, 2006, 32(3): 100-102

[5] Zhou Shui-xing, Hu Mian-yi, Zhou Xian-ying, Mechanics Analysis of Half-through CFST Arch Bridges with Different Bridge Deck Types, Journal of Highway and Transportation Research and Development, 2005, 22(4):57-60

[6] Hu Mianyi, Zhou Shuixing, Zhou Xianying, Analysis of the Best Bridge Deck s Relative Position for Long-span Half-through CFST Arch Bridge,. Journal of Highway and Transportation Research and Development, 2005, 22(6):82-84

[7] ZHANG Yang, SHAO Xu-dong and etc. Spatial Nonlinear Finite Element Analysis for Long-Span Trussed CFST Arch Bridge, China Journal of Highway and Transport, 2006, 19(4): 65-70

[8] WANG Yijun, QIAO Jiandong, Statics and dynamic annly sis of maocaojie bridge, Technological Development of Enterprise, 2003, 10: 7-8

[9] WANG Hao, QIAO Jiandong and etc. Seismic Response Spectrum Analysis of Maocaojie Bridge. Journal of Seismology, 2003, 23(3): 62-65 